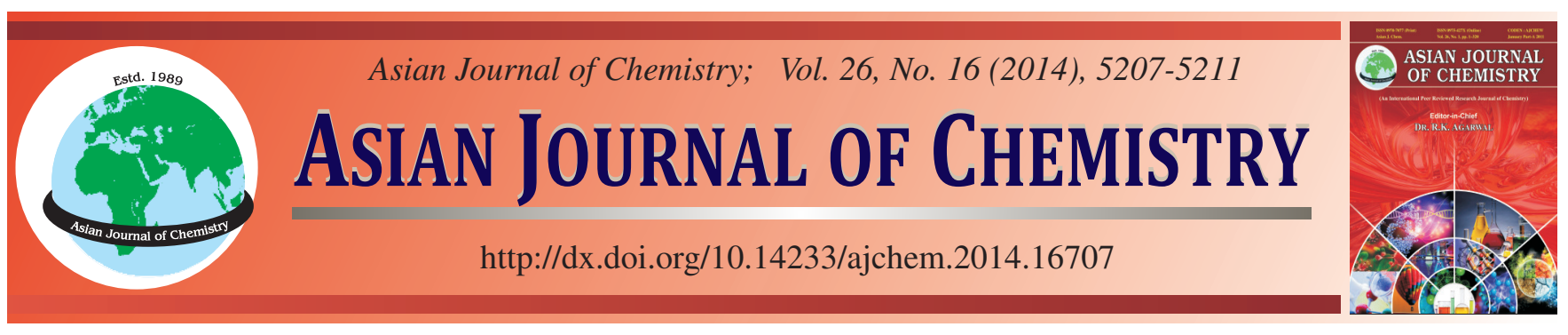

\title{
Multicomponent One-pot Green Synthesis of 1-Amidoalkyl-2-naphthols Promoted by $p$-Nitrobenzoic Acid Under Solvent-free Condition
}

\author{
Tiangang Li ${ }^{1, \dagger}$, Xing Zhai ${ }^{1, \dagger}$, Dharamveer Singh ${ }^{2}$, Rajesh K. Singh ${ }^{2, *}$ and Xuegong Xu ${ }^{3, *}$
}

\author{
${ }^{1}$ Beijing University of Chinese Medicine, Beijing 100029, P.R. China \\ ${ }^{2}$ Department of Pharmaceutical Chemistry, Shivalik College of Pharmacy, Nangal-140 126, India \\ ${ }^{3}$ Zhengzhou Traditional Chinese Medicine Hospital, Zhengzhou, P.R. China
}

*Corresponding authors: E-mail: rksingh244@gmail.com; xgxzhengzhou@126.com

$\dagger$ Both authors contributed equally to this paper.

Received: 16 November 2013;

Accepted: 2 January 2014;
Published online: 28 July 2014;

AJC-15663

\begin{abstract}
A series of sixteen 1-amidoalkyl-2-naphthols derivatives were synthesized by one-pot multicomponent condensation reaction of $\beta$-naphthol with various aromatic aldehydes and amides under thermal (hot plate and oil bath) and microwave irradiation techniques promoted by $p$ nitrobenzoic acid and the corresponding products were obtained in good to excellent yield (82-92\%) under solvent-free condition.
\end{abstract}

Keywords: 1-Amidoalkyl-2-naphthol, $p$-Nitrobenzoic acid, Multicomponent one-pot reaction, Microwave irradiation, Solvent-free.

\section{INTRODUCTION}

Since the last decade, there is a tremendous growth of research in the field of one-pot multicomponent reactions for the synthesis of wide variety of organic compounds. One of the multicomponent reactions of current interest is synthesis of 1-amidoalkyl-2-naphthols. The amidoalkyl-naphthols derivatives were paid much attention in synthetic organic chemistry for their various biological activities. It has been reported that 1-amidoalkyl-2-naphthols can be converted to biological active 1-aminoalkyl-2-naphthols derivatives by an amide hydrolysis reaction exhibiting depressor and bradycardic activities in humans ${ }^{1-2}$. In addition, 1-amidoalkyl-2-naphthols can also be converted to 1,3-oxazine derivatives ${ }^{3-4}$ which has widespread area of useful biological activities ${ }^{5-11}$. It has been reported to be an essential synthons for drug design and discovery of potent drugs such as nucleoside antibiotics and HIV protease inhibitors such as ritonavir and lipinavir ${ }^{12,13}$.

During last few years various methods have been reported for the synthesis of amidoalkyl-naphthols in the presence of variety of catalysts such as chlorosulphonic acid ${ }^{14}, p$-toluene sulphonic acid ${ }^{15}, \mathrm{NaHSO}_{4} \cdot \mathrm{H}_{2} \mathrm{O}_{16}, \mathrm{Fe}\left(\mathrm{HSO}_{4}\right)_{3}{ }^{17}, \mathrm{Sr}(\mathrm{OTf})_{2}{ }^{18}$, iodine $^{19}$, hetropoly acid $\mathrm{K}_{5} \mathrm{CoW}_{12} \mathrm{O}_{40} \cdot 3 \mathrm{H}_{2} \mathrm{O}^{20}$, hetropoly acid catalysts like cation-exchange resins ${ }^{21}$, silica supported perchloric acid ${ }^{22,23}, \mathrm{FeCl}_{3} \cdot \mathrm{SiO}_{2}{ }^{24}$, montmorillonite $\mathrm{K} 10$ clay ${ }^{25}$, silica sulfuric acid ${ }^{26}$, sulfamic $\operatorname{acid}^{27}, N, N, N^{\prime}, N^{\prime}$-tetrabromobenzene-1,3-disulfonamide ${ }^{28}$ and ionic liquids ${ }^{29}$. However, majority of them suffer from several limitations such as high temperature, long reaction time, the use of expensive reagents, low yields of products, high catalyst loading, corrosive reagents, strongly acidic conditions and further purification of products. Therefore development and introduction of convenient and efficient methods for the preparation of 1-amidoalkyl-2naphthols is of practical importance is still in demand.

In recent years, green and sustainable chemistry has become a subject of intensive research and the studies in this area have led the development of cleaner and relatively benign chemical processes. Among them, much effort has been devoted towards multicomponent and microwave assisted organic synthesis $(\mathrm{MAOS})^{30}$.

In continuation of our earlier work in the development of novel catalysts for the synthesis of various heterocyclic and synthetic intermediates ${ }^{31}$, we now describe a simple, general and efficient protocol for the synthesis of 1-amidoalkyl-2naphthols via one-pot condensation reaction using catalytic amount of $p$-nitrobenzoic acid using thermal and microwave techniques by Method A, B and C. The synthetic approach is outlined in (Scheme-I).

The $p$-nitrobenzoic acid is readily available, inexpensive reagents and environmentally benign light yellow crystals which is stable and can conveniently be handled and removed from the reaction mixture. Thus, the remarkable catalytic activities together with their operational simplicity make them the most suitable catalyst for the synthesis of 1-amidoalkyl-2naphthols. The $p$-nitrobenzoic acid has earlier been used for the efficient synthesis of 1,5 -benzodiazepines ${ }^{32}$. 
<smiles>[R]c1ccc(C(NC(C)=O)c2c(O)ccc3ccccc23)cc1</smiles>

\section{Method A: Microwave irradiation \\ Method B: Oil bath \\ Method C: Hot plate}

Scheme-I: Synthesis of 1-amidoalkyl-2-naphthols

\section{EXPERIMENTAL}

All the chemicals were purchased from commercial suppliers. The melting points were determined on Veegoprogrammable melting point apparatus (microprocessor based) and are uncorrected. ${ }^{1} \mathrm{H}$ NMR spectra were obtained using Brucker AC-400 F, 400 MHZ spectrometer. IR spectra were obtained on Perkin Elmer 882 Spectrum and RXI, FT-IR. Elemental analyses for $\mathrm{C}, \mathrm{H}$ and $\mathrm{N}$ were performed on Thermoflash EA-1112 CHNS-O Analyzer. Reactions were monitored and the homogeneity of the products was checked by TLC. All chemicals were dried and freshly prepared prior to use according to standard procedure.

\section{General procedure for synthesis of 1-amidoalkyl-2-naphthols}

Method A: A mixture of substituted aromatic aldehydes (1 mmol), 2-naphthol (1 mmol) and substituted amides (1.2 mmol) in the presence of effective amount of $p$-nitrobenzoic acid (30 mol \%, $0.3 \mathrm{mmol}$ ) were taken in $20 \mathrm{~mL}$ conical flask and was subjected to microwave irradiation in microwave oven (LG model MS1927C) at $450 \mathrm{~W}$ and each pulse was of $30 \mathrm{~s}$ for the appropriate time to avoid overheating. The progress of reactions was monitored by TLC (ethyl acetate $/ n$-hexane $=$ $2: 8)$. After completion of the reaction, a solid was obtained. It was washed with water and filtered. Then the solid residue was recrystallized from ethanol to get purified product.

Method B: A mixture of substituted aromatic aldehydes (1 mmol), 2-naphthol (1 mmol) and substituted amides (1.2 $\mathrm{mmol})$ in the presence of effective amount of $p$-nitrobenzoic acid (30 mol \%, $0.3 \mathrm{mmol}$ ) were taken in $100 \mathrm{~mL}$ conical flask and heated in an oil bath at $110-120{ }^{\circ} \mathrm{C}$ for the appropriate time with occasionally stirring. The progress of the reaction was monitored by TLC. After completion of reaction, mass was cooled to room temperature, washed with water and filtered. The solid residue was purified by recrystallization from EtOH to get purified product.

Method C: A mixture of substituted aromatic aldehydes (1 mmol), 2-naphthol (1 mmol) and substituted amides (1.2 $\mathrm{mmol})$ in the presence of effective amount of $p$-nitrobenzoic acid (30 mol \%, $0.3 \mathrm{mmol}$ ) were crushed in mortar and pestle to a fine powder and transferred into a china dish and heated on hot plate at $110-120^{\circ} \mathrm{C}$ for appropriate time with occasional stirring. After completion of the reaction, water $(10 \mathrm{~mL})$ was added, filtered and then residue recrystallized from ethyl alcohol to get pure product.
All the products were identified by their ${ }^{1} \mathrm{H}$ NMR, IR and $\mathrm{CHN}$ data and compared with literature reports.

\section{Spectral data for 1-amidoalkyl-2-naphthols}

N-[(2-Hydroxynaphthalen-1-yl)-phenyl-methyl)]acetamide (4a): IR( $\left.\mathrm{KBr}, \mathrm{v}_{\max }, \mathrm{cm}^{-1}\right): 3441(\mathrm{O}-\mathrm{H}, \mathrm{Ar}, \mathrm{str}), 3177$ (N-H 2 sec-amide, str), 3057 (C-H, Ar, str), 1694 (>C=O, amide, str), 1555-1462 (C=C, Ar, str), 1243-1095 (C-N/C-O, str), 770 (C-H, Ar, out of plane, bend), $746(\mathrm{~N}-\mathrm{H}$, out of plane, bend); ${ }^{1} \mathrm{H}$ NMR (400 MHz, DMSO- $\left.d_{6}\right): \delta 9.85$ (s, $\left.1 \mathrm{H},-\mathrm{CONH}\right)$, 8.27 (d, $J=12 \mathrm{~Hz}, \mathrm{Ar}-\mathrm{OH}) 7.97$ (t, $J=8 \mathrm{~Hz}, 1 \mathrm{H}, \mathrm{Ar}-\mathrm{H}), 7.75$ (d, $J=8 \mathrm{~Hz}, 1 \mathrm{H}, \mathrm{Ar}-\mathrm{H}), 7.69$ (d, $J=8 \mathrm{~Hz}, 1 \mathrm{H}, \mathrm{Ar}-\mathrm{H}), 7.40-$ 7.12 (m, 9H, Ar-H), 2.04 (s, 3H, - $\mathrm{COCH}_{3}$ ); Anal. calcd. (\%) for $\mathrm{C}_{19} \mathrm{H}_{17} \mathrm{NO}_{2}$ : C 78.33, H 5.87, N 4.81; Found (\%): C 77.47, $\mathrm{H}$ 5.79, N 4.76.

N-[(4-Chlorophenyl)-(2-hydroxynaphthalen-1-yl)methyl)]urea (4d): IR (KBr, $\left.v_{\max }, \mathrm{cm}^{-1}\right): 3320(\mathrm{O}-\mathrm{H}, \mathrm{Ar}, \mathrm{str})$, 3179 (N-H 2 sec-amide, str), 3022 (C-H, Ar, str), 1694 (>C=O, amide, str), 1592-1431 (C=C, Ar, str), 1402-1107 (C-N/C-O, str), 803 (C-H, Ar, out of plane, bend), 830 (C-Cl, str), 744 (N-H, out of plane, bend); ${ }^{1} \mathrm{H}$ NMR (400 MHz, DMSO- $\left.d_{6}\right): \delta$ 8.75 (s, 1H, -CONH ), 7.88-7.83 (m, 4H, Ar-H), 7.40-7.27 (m, 7H, Ar-H), 7.59 (d, J = $8 \mathrm{~Hz}, \mathrm{Ar}-\mathrm{OH}), 6.09$ (bs, 2H, - $\mathrm{NH}_{2}$ ); Anal. calcd. (\%) for $\mathrm{C}_{18} \mathrm{H}_{15} \mathrm{~N}_{2} \mathrm{O}_{2} \mathrm{Cl}$ : C 66.16, $\mathrm{H}$ 4.63, N 8.57; Found (\%): C 66.20, H 4.57, N 8.63.

N-[(4-Dimethylaminophenyl)-(2-hydroxynaphthalen1-yl)-methyl)] acetamide (4h): IR ( $\left.\mathrm{KBr}, \mathrm{v}_{\max }, \mathrm{cm}^{-1}\right): 3372$ (O-H, Ar, str), 3248 (N-H 2 sec-amide, str), 3084 (C-H, Ar, str), 2924 (C-H, alkane, str), 1652 (>C=O, amide, str), 15811397 (C=C, Ar, str), 1372-1031 (C-N/C-O, str), 827 (C-H, Ar, out of plane, bend), 698 (N-H, out of plane, bend); ${ }^{1} \mathrm{H}$ NMR $\left(400 \mathrm{MHz}, \mathrm{DMSO}-d_{6}\right): \delta 9.68(\mathrm{~s}, 1 \mathrm{H},-\mathrm{CONH}), 7.90(\mathrm{~d}, J=$ $8 \mathrm{~Hz}, \mathrm{Ar}-\mathrm{OH}), 7.89-7.06$ (m, 10H, Ar-H), 6.73 (s, 1H, -CHNH), $3.10\left(\mathrm{~s}, 6 \mathrm{H},-\mathrm{N}\left(\mathrm{CH}_{3}\right)_{2}\right), 2.13\left(\mathrm{~s}, 3 \mathrm{H},-\mathrm{COCH}_{3}\right)$; Anal. calcd. (\%) for $\mathrm{C}_{21} \mathrm{H}_{22} \mathrm{~N}_{2} \mathrm{O}_{2}$ : C 75.44, $\mathrm{H}$ 6.58, $\mathrm{N}$ 8.38; Found (\%): C 75.76, H 6.84, N 8.36.

N-[(4-Methyphenyl)-(2-hydroxy-naphthalen-1-yl)methyl)]benzamide (4k): IR ( $\left.\mathrm{KBr}, \mathrm{v}_{\max }, \mathrm{cm}^{-1}\right)$ : $3414(\mathrm{~N}-\mathrm{H} 2$ sec-amide, str), 3008 (O-H, Ar, str overlapping with C-H, Ar, str), 2824 (C-H, alkane, str), 1630 (C=O, amide, str), 15291483 (C=C, Ar, str), 1346-1248 (C-N/C-O, str), 817 (C-H, Ar, out of plane, bend), 711 (N-H, out of plane, bend); ${ }^{1} \mathrm{H}$ NMR (400 MHz, DMSO- $d_{6}$ ): $\delta 10.20$ (s, $1 \mathrm{H},-\mathrm{CONH}$ ), 8.93 (br d, $J$ $=8 \mathrm{~Hz}, 1 \mathrm{H} \mathrm{Ar}-\mathrm{OH}), 7.84-7.70(\mathrm{~m}, 4 \mathrm{H}, \mathrm{Ar}-\mathrm{H}), 7.51-7.16(\mathrm{~m}$, $9 \mathrm{H}, \mathrm{Ar}-\mathrm{H}), 7.02$ (d, $J=8 \mathrm{~Hz}, 2 \mathrm{H}, \mathrm{Ar}-\mathrm{H}), 2.23$ (s, 3H, $-\mathrm{CH}_{3}$ ); 
Anal. calcd. (\%) for $\mathrm{C}_{25} \mathrm{H}_{21} \mathrm{NO}_{2}$ : C 81.72, H 5.76, N 3.81; Found (\%): C 81.63, H 5.68, N 3.88 .

N-[(3-Nitrophenyl)-(2-hydroxynaphthalen-1-yl)methyl)]urea (4l): IR (KBr, $\left.\mathrm{v}_{\max }, \mathrm{cm}^{-1}\right): 3636(\mathrm{O}-\mathrm{H}, \mathrm{Ar}, \mathrm{str})$, 3399-3316 (N-H 2 sec-amide, str), 3183-3076 (C-H, Ar, str), 1640 ( $>\mathrm{C}=\mathrm{O}$, amide, str), 1481-1436 (C=C, Ar, str), 1346-1068 (C-N/C-O, str), 1528 (N-O, str), 810 (C-H, Ar, out of plane, bend), 744 (N-H, out of plane, bend); ${ }^{1} \mathrm{H}$ NMR (400 MHz, DMSO- $\left.d_{6}\right): \delta 8.93$ (s, $\left.1 \mathrm{H},-\mathrm{CONH}\right), 8.64(\mathrm{~d}, \mathrm{~J}=8 \mathrm{~Hz}, \mathrm{Ar}-\mathrm{OH})$, 8.11-7.60 (m, 7H, Ar-H), 7.59-7.23 (m, 3H, Ar-H), 6.88 (s, 2H, $-\mathrm{NH}_{2}$ ), 6.36 (s, $1 \mathrm{H},-\mathrm{CHNH}$ ); Anal. calcd. (\%) for $\mathrm{C}_{18} \mathrm{H}_{15} \mathrm{~N}_{3} \mathrm{O}_{4}$ : C 64.09, H 4.48, N 12.46; Found (\%): C 64.16, H 4.56, N 12.38.

N-[(2,5-Dimethoxyphenyl)-(2-hydroxynaphthalen-1yl)-methyl)]acetamide (4o): IR ( $\left.\mathrm{KBr}, \mathrm{v}_{\max }, \mathrm{cm}^{-1}\right): 3367(\mathrm{O}-$ $\mathrm{H}$, Ar, str overlapping with N-H 2 sec-amide, str), 3056 (C-H, Ar, str), 2927-2832 (C-H, alkane, str), 1640 (>C=O, amide, str), 1595-1408 (C=C, Ar, str), 1235-1043 (C-N/C-O, str), 814 (C-H, Ar, out of plane, bend), 748 (N-H, out of plane, bend); ${ }^{1} \mathrm{H}$ NMR (400 MHz, DMSO- $d_{6}$ ): $\delta 9.68$ (s, $\left.1 \mathrm{H},-\mathrm{CONH}\right), 8.45$ $(\mathrm{d}, J=8 \mathrm{~Hz}, 1 \mathrm{H}),-7.88-7.04$ (m, 9H, Ar-H), 6.45 (s, 1H, -CHNH), 3.62 (s, 3H, $\left.-\mathrm{OCH}_{3}\right), 3.45$ (s, 3H, -OCH3), 1.87 (s, 3H, $\left.-\mathrm{COCH}_{3}\right)$; Anal. calcd. (\%) for $\mathrm{C}_{21} \mathrm{H}_{21} \mathrm{NO}_{4}$ : C 71.78, H 6.02, N 3.99; Found (\%): C 71.50, H 6.50, N 3.90.

N-[(4-Chloro-phenyl)-(2-hydroxynaphthalen-1-yl)methyl)]nicotinamide (4p): IR $\left(\mathrm{KBr}, \mathrm{v}_{\max }, \mathrm{cm}^{-1}\right): 3340(\mathrm{~N}-\mathrm{H}$, 2 sec-amide, str), 3200 (O-H, Ar, str), 3057-3021(C-H, Ar, str), 1654 ( $>\mathrm{C}=\mathrm{O}$, amide, str), 1596-1464 (C=C, Ar, str), 1371-1032 (C-N/C-O, str), 883-856 (C-H, Ar, out of plane, bend), 738 (C-Cl, str), 716 (N-H, out of plane, bend); ${ }^{1} \mathrm{H}$ NMR $(400 \mathrm{MHz}$, DMSO- $\left.d_{6}\right): \delta 8.55$ (d, $\left.J=8 \mathrm{~Hz}, \mathrm{Ar}-\mathrm{OH}\right), 7.89-7.85$ (m, 4H, Ar-H), 7.62-7.13 (m, 10H, Ar-H), 6.66 (s, 1H, -CHNH); Anal. calcd. (\%) for $\mathrm{C}_{21} \mathrm{H}_{21} \mathrm{NO}_{4}$ : C 71.78, H 4.37, N 7.20; Found (\%): C 71.10, $\mathrm{H} 4.51$, N 7.95.

\section{RESULTS AND DISCUSSION}

In order to optimize the quantity of $p$-nitrobenzoic acid, we carried out the synthesis of N-[4-chloro-phenyl-(2hydroxynapthalene-1-yl)-methyl] acetamide by using 2naphthol, 4-chloro benzaldehyde and acetamide in the ratio (1:1:1.2 mmol) with different quantities of $p$-nitrobenzoic acid at same temperature and time under solvent free conditions. It was found that the best result was obtained when the reaction was carried in the presence of $0.3 \mathrm{mmol}$ ( $30 \mathrm{~mol} \%$ ) of $p$-nitrobenzoic acid (Table-1, Entry-3). The fewer amounts gave a low yield even after long reaction time and the more amounts could not cause the obvious increase for the yield of product. Therefore, $0.3 \mathrm{mmol}$ of catalyst was chosen as the optimal quantity of $p$-nitrobenzoic acid.

Slight excess of amide was found to be advantageous. Hence, molar ratio of aromatic aldehyde to amide was kept to be $(1: 1.2 \mathrm{mmol})$. Encouraged by these results, a wide variety of aromatic aldehydes and amides were treated with $\beta$-naphthol using $p$-nitrobenzoic acid under the optimized conditions to afford the corresponding 1-amidoalkyl-2-naphthols (Table-2) in good to excellent yields at $110-120{ }^{\circ} \mathrm{C}$ without formation of any side products such as dibenzoxanthenes, which are normally observed under the influence of strong acids. It is important to note that the synthesis of 1-amidoalkyl-2-naphthols could not be achieved in the absence of catalyst.
TABLE-1

OPTIMIZATION STUDY OF $p$-NITROBENZOIC ACID (PNBA) FOR THE SYNTHESIS OF 1-AMIDOALKYL-2-NAPHTHOLS

\begin{tabular}{ccccc}
\hline Entry & $\begin{array}{c}\text { PNBA } \\
(\mathrm{mmol})\end{array}$ & $\begin{array}{c}\text { Method A } \\
\text { Time }(\mathrm{min}) / \\
\text { yield }(\%) \\
\text { (Microwave) }\end{array}$ & $\begin{array}{c}\text { Method B } \\
\text { Time } \\
(\min ) / \\
\text { yield }(\%) \\
\text { (Oil-bath) }\end{array}$ & $\begin{array}{c}\text { Method C time } \\
(\text { min)/ yield }(\%) \\
\text { (Hot-plate) }\end{array}$ \\
\hline 1. & 0.1 & $10 / 75$ & $15 / 71$ & $20 / 56$ \\
2. & 0.2 & $10 / 82$ & $15 / 80$ & $20 / 62$ \\
3. & 0.3 & $10 / 88$ & $15 / 85$ & $20 / 66$ \\
4. & 0.4 & $10 / 88$ & $15 / 86$ & $20 / 66$ \\
\hline
\end{tabular}

TABLE-2

p-NITROBENZOIC ACID (PNBA) (0.3 mmol, $30 \mathrm{~mol} \%)$ CATALYZED SYNTHESIS OF 1-AMIDOALKYL-2-NAPHTHOLS

\begin{tabular}{|c|c|c|c|c|c|c|c|}
\hline \multirow[b]{2}{*}{ Entry } & \multirow[b]{2}{*}{$\mathrm{R}$} & \multirow[b]{2}{*}{$\mathrm{R}_{1}$} & \multirow[b]{2}{*}{ Product $^{\mathrm{a}}$} & \multicolumn{3}{|c|}{ Time $(\min ) / Y i e l d(\%)$} & \multirow[b]{2}{*}{$\begin{array}{c}\text { m.p. }\left({ }^{\circ} \mathrm{C}\right) \\
\text { (Lit.) }\end{array}$} \\
\hline & & & & $\begin{array}{c}\text { Method } \\
\text { A }\end{array}$ & $\begin{array}{c}\text { Method } \\
\text { B }\end{array}$ & $\begin{array}{c}\text { Method } \\
\text { C }\end{array}$ & \\
\hline 1 & $\mathrm{H}$ & $\mathrm{CH}_{3}$ & $4 a$ & $10 / 88$ & $15 / 85$ & $20 / 66$ & $\begin{array}{c}242-245 \\
(245-246)^{22}\end{array}$ \\
\hline 2 & $\mathrm{H}$ & $\mathrm{NH}_{2}$ & $4 b$ & $11 / 85$ & $16 / 86$ & $19 / 65$ & $\begin{array}{c}171-172 \\
(170-173)^{29 b}\end{array}$ \\
\hline 3 & $\mathrm{H}$ & $\mathrm{C}_{6} \mathrm{H}_{5}$ & $4 c$ & $9 / 83$ & $16 / 85$ & $19 / 67$ & $\begin{array}{c}234-237 \\
(234-236)^{15}\end{array}$ \\
\hline 4 & $4-\mathrm{Cl}$ & $\mathrm{NH}_{2}$ & $4 d$ & $8 / 90$ & $16 / 88$ & $25 / 72$ & $\begin{array}{c}165-167 \\
(166-168)^{29 b}\end{array}$ \\
\hline 5 & $4-\mathrm{Cl}$ & $\mathrm{CH}_{3}$ & $4 e$ & $9 / 92$ & $14 / 88$ & $23 / 74$ & $\begin{array}{c}222-224 \\
(223-225)^{22}\end{array}$ \\
\hline 6 & $4-\mathrm{Cl}$ & $\mathrm{C}_{6} \mathrm{H}_{5}$ & $4 f$ & $8 / 91$ & $13 / 87$ & $21 / 74$ & $\begin{array}{c}173-175 \\
(175-177)^{29 b}\end{array}$ \\
\hline 7 & $4-\mathrm{N}\left(\mathrm{CH}_{3}\right)_{2}$ & $\mathrm{NH}_{2}$ & $4 g$ & $11 / 87$ & $20 / 85$ & $25 / 70$ & 205-207 \\
\hline 8 & $4-\mathrm{N}\left(\mathrm{CH}_{3}\right)_{2}$ & $\mathrm{CH}_{3}$ & 4h & $14 / 84$ & $26 / 82$ & $28 / 64$ & $\begin{array}{c}122-124 \\
(123-125)^{24}\end{array}$ \\
\hline 9 & $4-\mathrm{CH}_{3}$ & $\mathrm{NH}_{2}$ & $4 \mathbf{i}$ & $12 / 82$ & $25 / 80$ & $32 / 62$ & $\begin{array}{c}120-122 \\
(118-120)^{17}\end{array}$ \\
\hline 10 & $4-\mathrm{CH}_{3}$ & $\mathrm{CH}_{3}$ & $\mathbf{4 j}$ & $14 / 83$ & $22 / 82$ & $30 / 61$ & $\begin{array}{c}222-224 \\
(222-223)^{24}\end{array}$ \\
\hline 11 & 4- $\mathrm{CH}_{3}$ & $\mathrm{C}_{6} \mathrm{H}_{5}$ & $4 k$ & $12 / 82$ & $24 / 79$ & $23 / 60$ & $\begin{array}{c}1190-191 \\
(190-192)^{29 c}\end{array}$ \\
\hline 12 & $3-\mathrm{NO}_{2}$ & $\mathrm{NH}_{2}$ & 41 & $8 / 92$ & $13 / 89$ & $20 / 72$ & $\begin{array}{c}192-194 \\
(194-196)\end{array}$ \\
\hline 13 & $3-\mathrm{NO}_{2}$ & $\mathrm{CH}_{3}$ & $4 m$ & 9/92 & $16 / 88$ & $22 / 65$ & $\begin{array}{c}242-243 \\
(241-242)^{22}\end{array}$ \\
\hline 14 & $3-\mathrm{NO}_{2}$ & $\mathrm{C}_{6} \mathrm{H}_{5}$ & $4 n$ & $9 / 89$ & $15 / 81$ & $21 / 67$ & $\begin{array}{c}213-215 \\
(214-216)^{29 b}\end{array}$ \\
\hline 15 & $2,5-\left(\mathrm{OCH}_{3}\right)_{2}$ & $\mathrm{CH}_{3}$ & 40 & $12 / 82$ & $20 / 80$ & $20 / 63$ & $\begin{array}{c}252-253 \\
(251-253)^{22}\end{array}$ \\
\hline 16 & $4-\mathrm{Cl}$ & $\mathrm{CH}_{3}$ & $4 p$ & $8 / 92$ & $12 / 90$ & $13 / 68$ & $209-211$ \\
\hline
\end{tabular}

${ }^{a}$ All known products have been reported previously in the literature and were characterized by comparison of IR and NMR spectra with authentic samples.

As reported in literatures, a mechanism for the synthesis of 1-amidoalkyl-2-naphthols is shown in Scheme-II. A role of $p$-nitrobenzoic acid has been proposed to activate the aldehyde by binding $\mathrm{H}^{+}$with the oxygen atom which ultimately enhances the electrophilicity of the aldehyde and leads to reduction in reaction time. The condensation of 2-naphthol with the activated aldehyde give ortho-quinone ( $o-\mathrm{QMs}$ ) as a highly reactive and ephemeral intermediate. The same orthoquinone methides, generated in situ, have been reacted with amide to form 1-amidoalkyl-2-naphthol derivatives. Thus, the 2-naphthol acts as Michael acceptors and araldehydes as nucleophile resulting in Michael adduct under the influence 


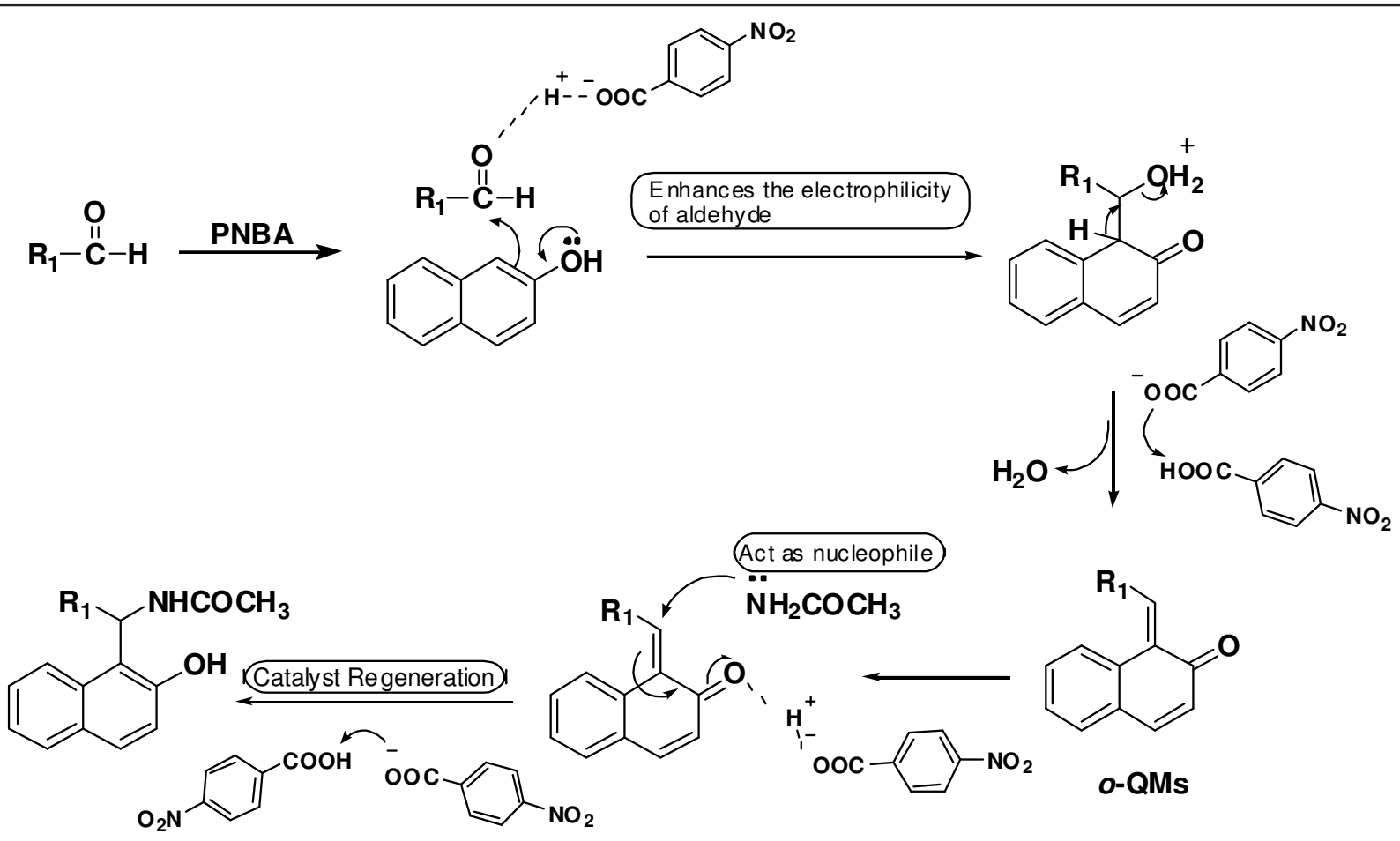

Scheme-II: Mechanism of action of p-nitrobenzoic acid promoted synthesis of 1-amidoalkyl-2-naphthols

of $p$-nitrobenzoic acid. The electron withdrawing groups (EWD) substituted on benzaldehyde in $o$-QM intermediate increase the rate of 1, 4-nucleophilic addition reaction because of alkene LUMO is at lower energy in the neighboring withdrawing groups than electron donating groups (EDG). Hence benzene ring with electron withdrawing groups gave better yield as compared to electron donating groups.

\section{Conclusion}

In conclusion, we have found $p$-nitrobenzoic acid as the best promoter for the synthesis of 1-amidoalkyl-2-naphthols under solvent-free conditions. It is noted that the solvent-free microwave irradiation can promote reactive pathways in very convenient way from green chemical point of view compared to the direct hot plate heating method. These advantages makes this protocol an attractive and user friendly alternative for the synthesis of 1-amidoalkyl-2-naphthols.

\section{ACKNOWLEDGEMENTS}

The authors gratefully acknowledged to College Managing Committee and Principal, Shivalik College of Pharmacy, Nangal, Punjab for constant encouragement and support. This research was supported by Project of Beijing University of Chinese Medicine (2014-JYB-JS078 hold by Tiangang Li) and Project of Beijing University of Chinese Medicine (14013 hold by Xing Zhai). Thanks are also due to SAIF, Panjab University, Chandigarh for cooperation in getting the spectral data.

\section{REFERENCES}

1. A.Y. Shen, C.T. Tsai and C.L. Chen, Eur. J. Med. Chem., 34, 877 (1999).

2. I. Szatmari and F. Fulop, Curr Org Synth, 1, 155 (2004).

3. M. Damodiran, N. Panneer Selvam and P.T. Perumal, Tetrahedron Lett., 50, 5474 (2009).
4. A.H. Kategaonkar, S.S. Sonar, K.F. Shelke, B.B. Shingate and M.S. Shingare, Org. Commun., 3, 1 (2010).

5. Y. Kusakabe, J. Nagatsu, M. Shibuya, O. Kawaguchi, C. Hirose and S. Shirato, J. Antibiot., 25, 44 (1972).

6. J.B. Chylinska, T. Urbanski and M. Mordarski, J. Med. Chem., 6, 484 (1963).

7. J.L. Peglion, J. Vian, B. Goument, N. Despaux, V. Audinot and M.J. Millan, Bioorg. Med. Chem. Lett., 7, 881 (1997).

8. H. Ren, S. Grady, D. Gamenara, H. Heinzen, P. Moyna, S. Croft, H. Kendrick, V. Yardley and G. Moyna, Bioorg. Med. Chem. Lett., 11, 1851 (2001).

9. F. Benedini, G. Bertolini, R. Cereda, G. Doná, G. Gromo, S. Levi, J. Mizrahi and A. Sala, J. Med. Chem., 38, 130 (1995).

10. R.D. Clark, J.M. Caroon, A.F. Kluge, D.B. Repke, A.P. Roszkowski, A.M. Strosberg, S. Baker, S.M. Bitter and M.D. Okada, J. Med. Chem., 26, 657 (1983).

11. J.B. Chylinska, M. Janowiec and T. Urbanski, Br. J. Pharmacol., 43, 649 (1971).

12. S. Knapp, Chem. Rev., 95, 1859 (1995).

13. S.M. Vrouenraets, W.F. Wit, J. Tongeren and J.M. Lange, Expert Opin. Pharmacother., 8, 851 (2007).

14. M. Anary-Abbasinejad, A. Hassanabadi, M. Kamali-Gharamaleki, A. Saidipoor, H. Anaraki-Ardakani, J. Chem. Res., 644 (2007).

15. H.R. Shaterian and H. Yarahmadi, Synlett, 916 (2006).

16. H.R. Shaterian and H. Yarahmadi, ARKIVOC, 105 (2007).

17. H.R. Shaterian, H. Yarahmadi and M. Ghashang, Bioorg. Med. Chem. Lett., 18, 788 (2008).

18. W.K. Su, W.Y. Tang, J.J. Li, J. Chem. Res., 123 (2008).

19. B. Das, K. Laxminarayana, B. Ravikanth and R. Rao, J. Mol. Catal. Chem., 261, 180 (2007).

20. L. Nagarapu, M. Baseeruddin, S. Apuri and S. Kantevari, Catal. Commun., 8, 1729 (2007).

21. S.B. Patil, P.R. Singh, M.P. Surpur and S.D. Samant, Synth. Commun., 37, 1659 (2007).

22. H.R. Shaterian, H. Yarahmadi and M. Ghashang, Tetrahedron, 64, 1263 (2008).

23. B. Das, D.N. Kumar, K. Laxminarayana and B. Ravikanth, Helv. Chim. Acta, 90, 1330 (2007).

24. H.R. Shaterian and H. Yarahmadi, Tetrahedron Lett., 49, 1297 (2008).

25. S. Kantevari, S.V.N. Vuppalapati and L. Nagarapu, Catal. Commun., 8, 1857 (2007).

26. G. Srihari, M. Nagaraju and M.M. Murthy, Helv. Chim. Acta, 90, 1497 (2007). 
27. (a) S.B. Patil, P.R. Singh, M.P. Surpur and S.D. Samant, Ultrason. Sonochem., 14, 515 (2007); (b) R.R. Nagawade and D.B. Shinde, Chin. J. Chem., 25, 1710 (2007).

28. R. Ghorbani-Vaghei and S.M. Malaekehpour, Cent. Eur. J. Chem., 8, 1086 (2010).

29. (a) A. Kumar, M.S. Rao, I. Ahmad and B. Khungar, Can. J. Chem., 87, 714 (2009); (b) H. Khabazzadeh, K. Saidi and N. Seyedi, J. Chem. Sci., 121, 429 (2009); (c) A.R. Hajipour, F. Ghayeb, N. Sheikhan and A.E. Ruoho, Tetrahedron Lett., 50, 5649 (2009); (d) S.B. Sapkal, K.F. Shelke, B.R. Madje, B.B. Shingate and M.S. Shingare, Bull. Korean Chem. Soc., 30, 2887 (2009); (e) T.T. She, Z.L. Liu and K. Gong, Chinese J. Appl. Chem., 27, 778 (2010).

30. (a) P.T. Anastas and J.C. Warner, Green Chemistry: Theory and Practice; Oxford University Press, Oxford, UK (1998); (b) P.T. Anastas and T. Williamson, Green Chemistry, Frontiers in Benign Chemical Synthesis and Process; Oxford University Press, Oxford, UK (1998).
31. (a) R. Duvedi and R.K. Singh, Asian J. Chem., 24, 5665 (2012); (b) S. Sharma, D.N. Prasad and R.K. Singh, J. Chem. Pharm. Res, 3, 382 (2011); (c) A. Sandhar, D.N. Prasad and R.K. Singh, Indian J. Heterocycl. Chem., 21, 369 (2012); (c) A. Sandhar, D.N. Prasad, A. Kapoor and R.K. Singh, Curr. Res. Chem., 4, 68 (2012); (d) S. Malik, S. Sharma and R.K. Singh, Asian J. Chem., 24, 5669 (2012); (e) P. Kaur, H. Sharma, R. Rana, D.N. Prasad and R.K. Singh, Asian J. Chem, 24, 5649 (2012); (f) A. Sandhar and R.K. Singh, Asian J. Chem., 24, 5643 (2012); (g) A. Sandhar and R.K. Singh, Chem. Sci. Trans., 2(S1), 176 (2012); (h) R.K. Singh, B. Singh, R. Duvedi and S. Kumar, Res. Chem. Intermed., (2014); doi:10.1007/s11164-013-1513-5.

32. R. Varala, R. Enugala and S.R. Adapa, J. Braz. Chem. Soc., 18, 291 (2007). 